\title{
Biomechanical Analysis of Sports Dance
}

\author{
Ganna Dorosh, Liudmyla Mova, Kateryna Lukianenko, Lidiia Shestopal, Daria Dehtiar, \\ Liudmyla Hladka
}

Department of Choreographic Art, Kyiv National University of Culture and Arts, Kyiv, Ukraine

Received July 24, 2021; Revised November 4, 2021; Accepted November 21, 2021

\begin{abstract}
Cite This Paper in the following Citation Styles
(a): [1] Ganna Dorosh, Liudmyla Mova, Kateryna Lukianenko, Lidiia Shestopal, Daria Dehtiar, Liudmyla Hladka , "Biomechanical Analysis of Sports Dance," International Journal of Human Movement and Sports Sciences, Vol. 9, No. 6, pp. 1420 - 1426, 2021. DOI: 10.13189/saj.2021.090638.
\end{abstract}

(b): Ganna Dorosh, Liudmyla Mova, Kateryna Lukianenko, Lidiia Shestopal, Daria Dehtiar, Liudmyla Hladka (2021). Biomechanical Analysis of Sports Dance. International Journal of Human Movement and Sports Sciences, 9(6), 1420 1426. DOI: 10.13189/saj.2021.090638.

Copyright $\bigcirc 2021$ by authors, all rights reserved. Authors agree that this article remains permanently open access under the terms of the Creative Commons Attribution License 4.0 International License

\begin{abstract}
Sports ballroom dancing is a type of sports activity that makes serious demands on the development of new motor actions, the manifestation of reaction speed, the ability to concentrate and switch attention, and many more parameters. Success in sports dance competitions depends not only on natural skills but also to a greater extent on a sportsman's practical training. The analysis of the biomechanics of sports dance and the characteristics of the sportsman's dynamic data suggest assessing the feasibility, efficiency, improvement of the technique of the performed motor action, which determines the goals of the development of the motor abilities of young sportsmen at an early stage. Based on knowledge of biomechanics, it is easier for a teacher to teach his pupils. But for this, it is necessary to be able to analyze motor activity and indicate the direction of active search, form a motor task and, based on the foundations of biomechanics, the necessary fundamentals of technology. Information about the biomechanical structure of the movement is used both in the formation of the technique of motor actions of beginner dancers and in its improvement in qualified dancers. This is what determines the relevance of the study; therefore, the purpose of the article is to identify the features of movements in sports dances using their biomechanical analysis. The authors carried out a theoretical and methodological analysis of special literature on biomechanical analysis of sports dance, which allowed them to analyze the movements of two dances. The analysis made it possible to reveal the peculiarities of the performance of these dances, which means that making adjustments to special preparatory exercises with a similar
\end{abstract}

amplitude of the knee joints will lead to better training of sportsmen. Also, this analysis effectively improves the skill level of performing dance steps by experienced dancers because it clearly shows all the features of the movement at a particular moment.

Keywords Biomechanical Analysis, Complex Coordination Sports, Sports, Sports Dance, Sportsman

\section{Introduction}

Sport dancing originated in England at the end of the 18 th century. Then dancing was a privilege of high society, an integral part of high-society balls $[1 ; 2]$. At the end of the 19th century, they became popular among other sectors of culture as well. In the $1920 \mathrm{~s}$, ballroom dancing competitions have begun. In 1924, in England, under the Imperial Society for Teachers' Performance, a Special Ballroom Dance Device was created, responsible for developing music, steps and dance technique. Gradually sport dances spread throughout Europe reached Asia and America $[3 ; 4 ; 5]$.

Sports ballroom dancing is a type of sports activity that shows strict requirements for developing new motor actions, the manifestation of reaction speed, the ability to adjust and establish attention. All these qualities or skills in the theory of physical education are associated with the concept of talent - a person's ability to quickly expediently, i.e. the most rational way is to master new motor actions, to 
solve motor tasks in changing conditions successfully.

In the training of sportsmen-dancers in modern sports, technical training is one of the most critical places. While a person has reached his limit in developing motor qualities, technological improvement comes out on top. It acquires great importance, a further increase in results is possible due to the advancement of technology and its deeper study. These characteristics determine the level of sports performance. Sports dances as a type of competitive activity are characterized by various movements of sportsmen-dancers, from the point of view of the presence of movements, accompanied by a change in the body's position and its individual parts in space. This diversity concerns the differences between each individual dance in the standard program. An up-to-date is a study of the technique of qualified dancers in performing curly elements in a standard program.

Information about the biomechanical structure is used both to form the technique of motor actions of beginner dancers and in its improvement in qualified dancers; this is what determines the relevance of the research.

Thus, the purpose of the study is to conduct a biomechanical analysis of the movements of sports dancers as a way to improve the training of sportsmen and improve the skills of already experienced dancers.

\section{Literature Review}

Biomechanics of human movements is a private science at the intersection of sciences: medicine, physics, mathematics, physiology, biophysics. It involves particular specialists in its sphere, such as engineers, designers, technologists, programmers, etc. Biomechanics is based on experimental research data, the most important of which are assessing various types of human motor activity, their control, determination of the properties of biomechanical systems with different deformation methods, and results obtained in solving medical and biological problems.

The study of human and animal movements began long before the birth of Leonardo da Vinci. He brilliantly described the kinematics of human actions; for the first time, he indicates that the skeleton is a system of levers activated by the muscles attached to them. Later, as science developed, many studies in this area worldwide appeared $[6 ; 7 ; 8 ; 9]$.

Romanenko \& Veretelnikova, in their study [10], determined biomechanical characteristics in percussion types of single combats and tested a computer program. The results obtained in the study made it possible to decide on the differences between the performed video computer analysis and the model values. V. Kashuba researched the same direction [11]: he studied the problems of measuring the parameters of an athlete's physical development, namely, the video computer analysis of the geometry of human body masses. In another study, he and a team of authors [12] carried out a correlation analysis between the resulting speed of the total centre of mass of the sportsmen' bodies and biomechanical characteristics. The authors have established that at the initial stages of training sportsmen, it is necessary to consider the biokinematic and biodynamic structure of the technique of motor actions. According to Khaled M. Zahran [13], computer modelling in training athletes specializing in weightlifting is one of the most promising ways to improve sports equipment. The importance of biomechanical analysis of movements for improving the sports technique of qualified athletes is proved by Krupenya \& Khmelnitskaya [14]. They substantiated the development of special programs for enhancing the sports technique of skilled gymnasts in vaults based on biomechanical video computer analysis of the kinematic structure of the technique of motor actions of the world's leading gymnasts. The proposed programs solve certain tasks to achieve those biomechanical indicators on which the sports result directly depends. There are many interesting works on biomechanical analysis of movements in fencing. Lysykh A. [15] devoted his dissertation research to considering cause-and-effect relationships between the biomechanical characteristics of attacking techniques, where he determined the discriminative signs of attacking actions technique in athletes of different qualifications. In the theory and practice of dancing, methods of biomechanical analysis, synthesis and modelling are also widely used, which allow the study of sportsmen of various qualifications to find rational ways of performing motor actions, which largely contributes to their faster and more qualitative mastering and improvement. He devoted his dissertation to the biomechanics of classical dance Gabovich, M. [16]. The biomechanical structure of performing steps back in sports dances was studied by I. Tarkhanov [17]. In his research, he analyzed backwards dance steps with their inherent biomechanical features, namely, the patterns of interaction with the support when performing backward dance steps at different rates among sportsmen of different qualifications. He proved that the study of the regularities of changes in the kinematic and dynamic characteristics of the movements of sportsmen-dancers when interacting with the support made it possible to identify biomechanical criteria for the rational technique of performing back steps.

Thus, a review of the literature has shown that biomechanics is one of the tools for improving the training of sportsmen. The practical application of biomechanical principles in dance opens up space for understanding the laws of forces acting both on the body and inside the body (musculoskeletal-neurological connections), preventing injuries and developing movement skills. The biomechanical analysis allows to "see the movement" if its characteristics (trajectory, speed, force, etc.) are registered, which allows analyzing motor activity and forming a motor task and, based on the foundations of biomechanics, the necessary fundamentals of technology. 


\section{Biomechanics of Sports Dance}

The biomechanics of sports studies the human body's capabilities, motor apparatus, and interconnected functioning of all body systems to help achieve the best sports result. There are studies on the biomechanics of various sports. The motor actions in sports dance are based on an ordinary step - a simple walk.

At its core, sports ballroom dance is a duet (pair) type of dance. Of course, there is a multi-duet (8 pairs) form formation, but the central unit is a pair and its performing level. The partner and the female partner create the final product - a sports ballroom pair - with their individual skills and performance skills in synthesis with pair interaction.

The main tasks of sports biomechanics are shown in Fig. 1.

The biomechanics of sports dance determines the principles of movement following the technical requirements of the dance program. It explains the patterns of motor actions of sportsmen, as well as the interaction of partners. When studying the patterns of motor actions in sports dances, the descriptions of the figures outlined in the corresponding literature on European and Latin American programs were used. The authors of these books identified the main external signs of the kinematics of dancers' movements and offered detailed descriptions of the sequence of steps, and determined what and in what order should be performed, but the motor processes in the human musculoskeletal system are much more complex than they are presented in textbooks describing the dance technique. Many factors influencing the qualitative characteristics of motor actions of performers remained outside the framework of the description of figures and dance technique. What happens to the moving body of a dancer? How does the musculoskeletal system function? According to what canons do partners interact with each other? Unfortunately, these issues are not addressed in the publications. They are a kind of register of figures describing the main steps, which is their main advantage. The lack of information about the construction of motor actions leads to a varied interpretation of their performance.

The exercises used to work out single motor actions and a complex of movements aggravate the situation. Biomechanics of sports dance determines motional actions' patterns and the best ways to solve motional problems to improve the dance technique.

\begin{tabular}{|l} 
Tasks of sports biomechanics \\
- improvement of sports equipment, modelling and design of its most rational options; \\
$\begin{array}{l}\text { - biomechanical control of the technique of individual sportsmen to correct mistakes and increase the level of } \\
\text { sports and technical skill; }\end{array}$ \\
$\begin{array}{l}\text { - revelation of biomechanical regularities of motor actions improvement; } \\
\text { an increase in skill and sports performance to assess the stage and final indicators on different training cycles; }\end{array}$ \\
- development of biomechanically expedient exercise equipment for sports.
\end{tabular}

Figure 1. Tasks of biomechanics in sports 


\section{Methodology}

A separate section in biomechanics - "biomechanics of choreographic exercises", which investigates the patterns of motional actions when performing choreographic training, elements of dance composition, determines the prospects for developing dancers' abilities. And such standard dance terms as balance, stability, balance are also standard terms in biomechanics. The choreographic concept of "stretching" is described in biomechanics as one of the types of muscle deformation, and any technical action in choreography (batman, "figure eight" of the hip joint and others) is nothing more than a bodily movement exercise. The significance of a bodily-motor exercise is determined by the understanding of its purpose and purpose.

Biomechanical analysis of human movements always begins with the determination of various characteristics of a moving body. These characteristics can be different mechanical characteristics (for example, displacement, speed, acceleration) and biological characteristics (muscle pulling force, time of total electrical activity of the muscle). Some of these characteristics are determined experimentally, and the rest - by calculation.

To study the features of the performance of basic elements and basic dance figures, a biomechanical video computer analysis was applied. Contrast markers were attached to the dancers' bodies at the locations of the anthropometric points. A scale bar, divided into ten-centimetre coloured areas, was placed next to the subjects. The webcam was positioned on a tripod motionless at a distance of 5-7 $\mathrm{m}$ to the subject. The optical axis of the camera lens was oriented perpendicular to the plane of the shooting object. Further, the resulting recorded video using the "freeze-frame" mode was processed, and biokinematic diagrams and biomechanical characteristics of dancers' movements were obtained when performing basic figures in each standard dance.

At the first stage, it is necessary to analyze the composition of the figure, the number of actions, what muscles they are carried out, and most importantly - why and how the action takes place. In other words, it is necessary to highlight the starting position, the path to follow and the final result - the goal. In improving the level of mastery of performing dance steps, an important goal is not the execution of a figure or a simple step but how they should be performed. Quality should not be behind a simple desire to take action.

The analysis of the biomechanics of sports dance and the characteristics of the sportsman's dynamic data suggest assessing the feasibility, efficiency, improvement of the technique of the performed motor action, and determining the development of the motor abilities' motor abilities of a young sportsman at an early stage.

\section{Results and Discussion}

The analysis of special literature has shown that, in the opinion of many authors, when studying the technique of motor actions, more attention should be paid to the peculiarities of the kinematic structure of motor actions of sportsmen, namely the tempo-rhythmic structure, the position of the pair and the technique of the essential elements of dance figures.

It should be noted that the following characteristics influence the tempo of the dance performance:

- the tempo of the music;

- time signature;

- the number of steps that the dancer performs in one measure;

- a combination of figures achieved by the dancer.

This tempo corresponds only to basic figures. When performing a competitive program by qualified couples, the pace will be significantly higher due to the execution of complex figures. The fastest and most intense dance is the Vienna Waltz. A unique feature is that his high tempo of 180 steps per minute does not change, and the figures of the right and left turns are performed cyclically, then Quickstep and Tango follow, and then Waltz and Foxtrot.

The peculiarity of the slow and Vienna waltz figures is that 3 steps are performed in 1 measure of the music in each figure. This means that there is 1 dance step for 1 beat of the music. The only exceptions are the chasse to the right and the chasse from the promenade position, where 2 steps are performed on the 2nd hit. However, the tempo of the slow waltz music is 30 bars per minute, and the Viennese music is 60 bars. Thus, dances with the same time signature have a different tempo of movement. Foxtrot's tempo is 30 beats per minute; in each measure, there are 4 beats for which the dancer performs 3 steps; thus, the tempo of the dancer's movement is 90 steps per minute, the duration of 1 measure of movement is $2 \mathrm{~s}$. The Quickstep tempo is $48-52$ beats per minute; in each measure, there are 4 beats, for which the dancer performs 2-4 steps; thus, the dancer's pace of movement is 96-156 steps per minute, the duration of 1 measure of movement is $1.15-1.25 \mathrm{~s}$.

Considering the partners' position relative to each other, at the moment of the beginning of the movement, it should be noted that the position should be maximally adapted for solving motor problems, taking into account the external and internal forces acting on the moving system of bodies. The dance position must be biostatically balanced before starting the movement. To solve this problem, during the research, a biomechanical analysis of the static stability of the position of a dancing couple in a standard dance program was carried out (Fig. 2). 
In the sagittal plane, the mass is evenly distributed over the support area, the stability coefficients in the anterior and posterior directions are 0.28 and 0.22 , respectively. The left stability coefficient of 0.56 is significantly higher in the frontal plane than the right one - 0.14. Stability is much higher on the part of the partner than on the part of the partner. The uneven distribution of masses relative to the support area is caused by the fact that the upper part of the partner's body is displaced relative to the centre of the pair, and the partner's body remains vertical (Fig. 2). Unlike the partner, the partner's position in the pair is not upright. The partner's spine angle is $27^{\circ}$ for highly qualified couples.

Fig. 3 shows the biokinematic diagram of the partner's movement when performing the "Right turn" figure in the Slow Waltz.
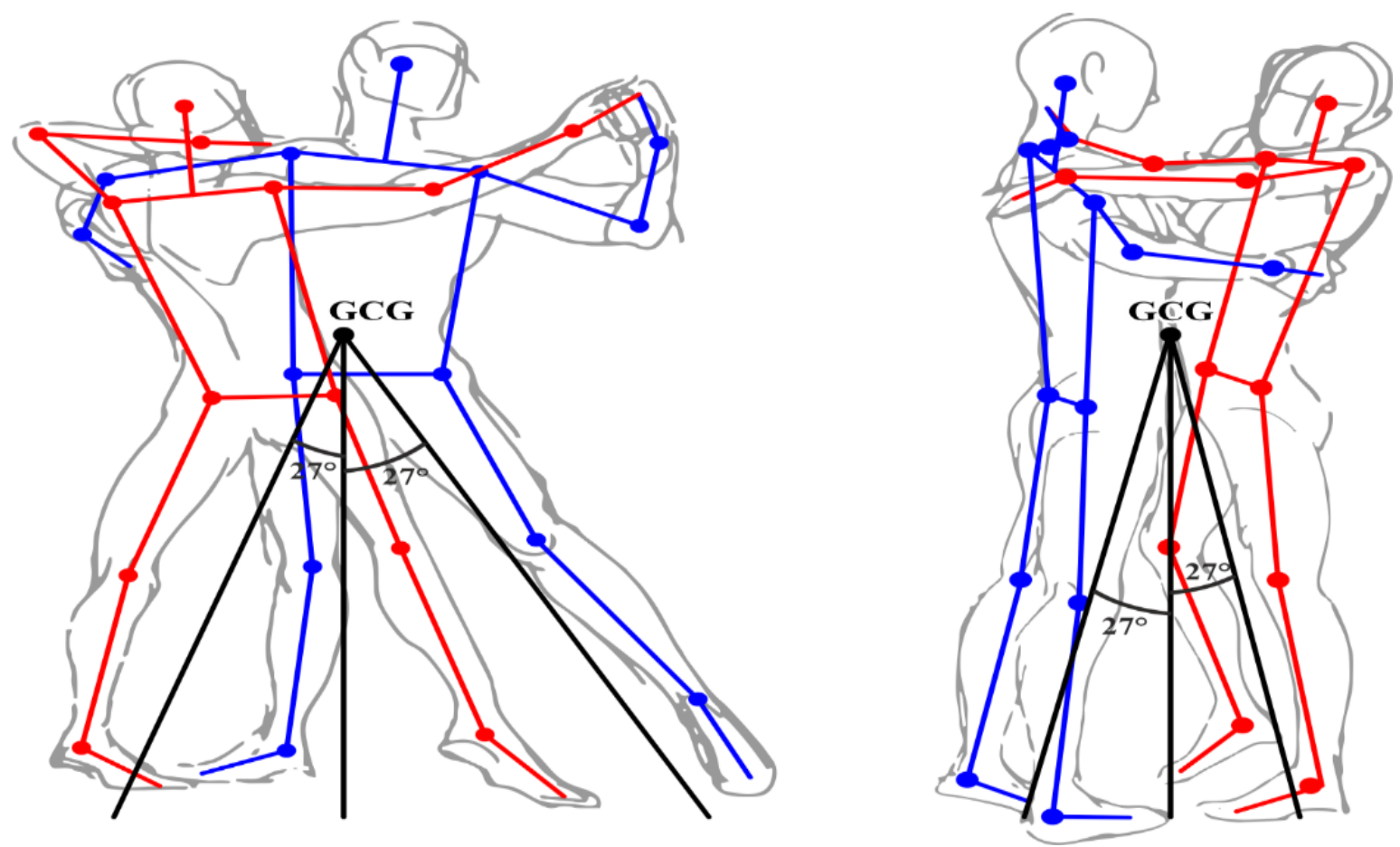

Figure 2. Biomechanical diagram of the static stability of the position of a dancing couple in a standard dance program

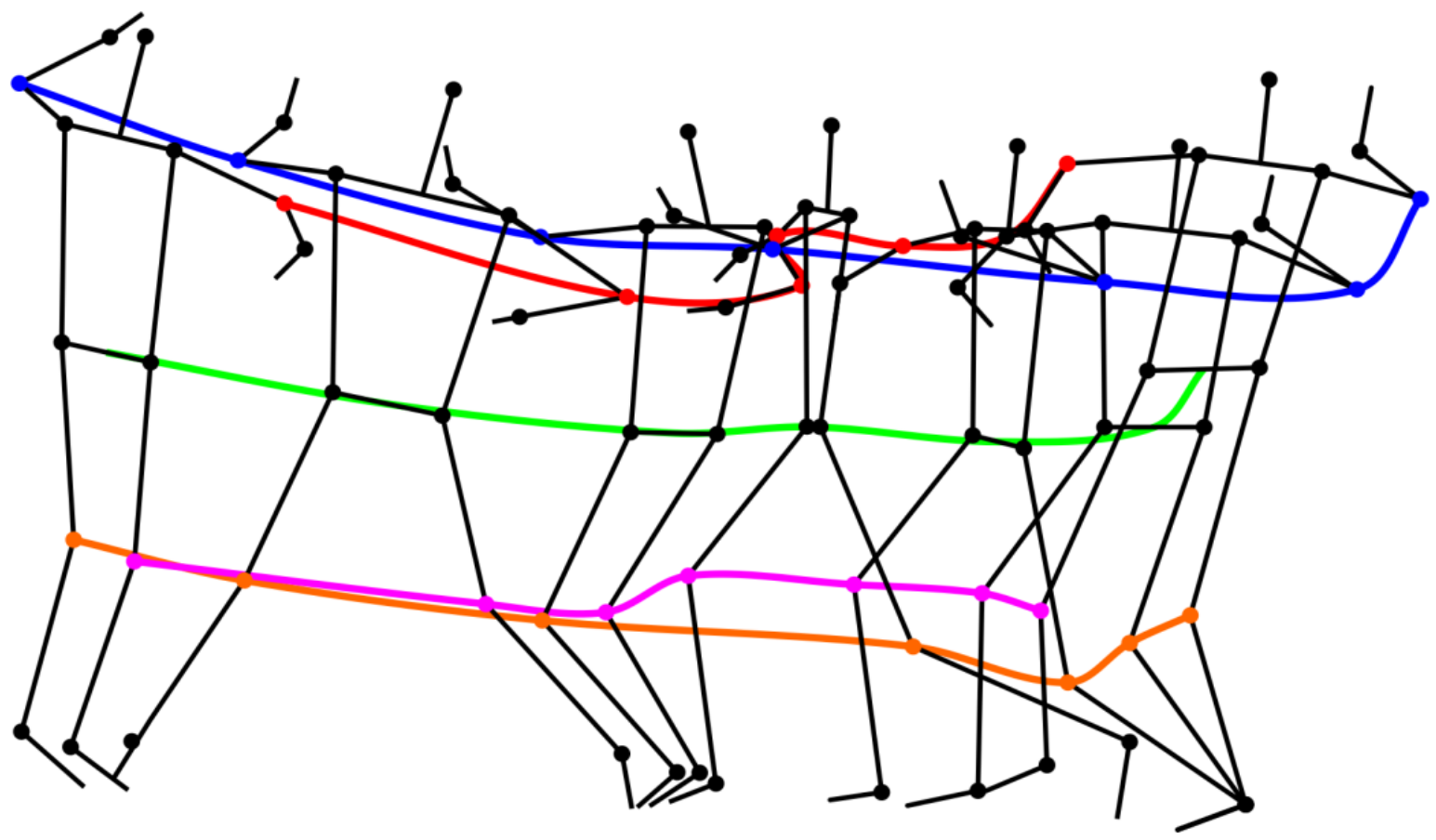

Figure 3. Biokinematic diagram of the partner's movement when performing the "Right turn" figure in the Slow Waltz 


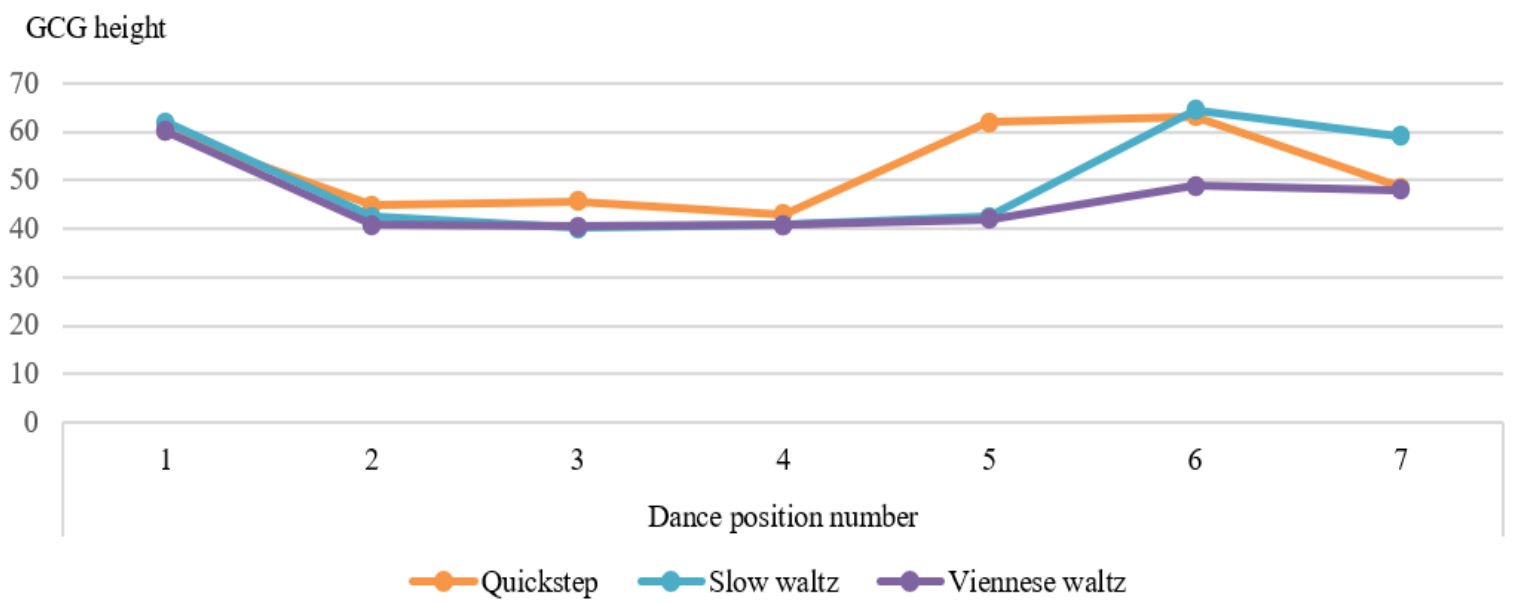

Figure 4. The trajectory of the GCG dancer in swing dances in a standard program (Slow and Viennese waltz)

This detailed demonstration of the partner's movement (emphasis on the elbow, hip and knee joints) during the execution of the pas will allow you to study in what position the parts of the dancer's body should be.

The dances of the standard program have a swing character, except tango. Swing is a pendulum movement of a dancer's body or part of the body relative to a fixed point or axis. The correct trajectory of body movement determines the quality of swing figures. The GCG trajectory is an arc, the lowest point at the beginning of the first step (damping phase).

Fig. 4 shows the movement trajectories in three "swing" dances: Quickstep, Slow and Viennese waltz, built based on the data obtained.

The study of trajectories is necessary to further develop special preparatory exercises with a similar amplitude of the joints.

The height of the general centre of gravity (GCG) is expressed as a percentage relative to the height of the dancer, which will allow an objective consideration of this indicator, despite the different heights of the subjects. In the Slow Waltz and the Vienna Waltz, the trajectory of the GCG is very similar, the lowest point is at the end of the pushing phase in the first step, but the amplitude of the rise in the slow waltz is more significant than in the Viennese.

The most significant amplitude of descents and ascents is present in the slow waltz; the difference between the highest and lowest points is just over $24 \%$. The smallest amplitude is found in the Viennese waltz dance and is over $12 \%$.

In the course of the work, the main essential elements of the technique of dance figures were analyzed, such as a step, lowering the body, lifting the body, tilting the body. The technique of performing all these elements depends on the spatial and temporal parameters of the dance. The slopes constantly change depending on the speed of the body in space.

The most significant value of the slope is observed in the slow waltz in the pushing phase at the 2 nd step and is $\mathrm{X}=$ $11^{\circ}, \mathrm{S}=0.04^{\circ}$. In the Viennese waltz, the slope in the pushing phase at the 2nd step is less than in the slow waltz, equal to $\mathrm{X}=7^{\circ}, \mathrm{S}=0.01^{\circ}$; this is since the tempo of the Viennese waltz is faster than the tempo of the slow waltz.

Lowering and lifting the dancer's torso is provided by flexion and extension of the knee, ankle and hip joints. Flexion of the knee joint provides a deeper descent. The most excellent flexion of the knee joint is observed in the amortization phase before pushing out from the supporting leg at the 2nd step in the Viennese waltz $X=107^{\circ} \mathrm{S}=7.9^{\circ}$.

These characteristics should be used when performing special preparatory exercises with a similar amplitude of the knee joints.

\section{Conclusions}

In our work, we analyzed the basic elements of three dances, which specialists in a standard dance program identify. The main basic elements are the position of the dancer and the couple's body, step, lowering the body, lifting the body, tilting the body, turning the dancer's body.

In a comparative biomechanical analysis of the kinematic structure of the technique of qualified dancers when performing the basic elements of dance figures, we revealed significant differences in the temporal and rhythmic structures, the kinematic structure of basic movements in various dances of the standard program (slow waltz, tango, Viennese waltz, foxtrot, quickstep).

The analysis made it possible to reveal the peculiarities of the performance of these dances, which means that making adjustments to special preparatory exercises with a similar amplitude of the knee joints will lead to better training of sportsmen.

In the process of improving the level of mastery of performing dance steps, an important goal is not the execution of a figure or a simple step but how they should be performed. It is in these two areas of training sportsmen that biomechanical analysis helps. 


\section{Limitations}

The article contains a small part of the theory of biomechanics of sports dance. Biomechanics is a voluminous topic that covers many aspects of the motional actions of a dance couple of any level. Many issues of interaction between partners and the peculiarities of the performance of a number of figures must be discussed separately.

The research was conducted in an ethical manner.

\section{REFERENCES}

[1] Gumenyuk, T., Frotveit, M., Bondar, I., Horban, Y., Karakoz, O. Cultural diplomacy in modern international relations: The influence of digitalization. Journal of Theoretical and Applied Information Technology, 99(7), pp. 1549-1560, 2021.

[2] Bondar, I., Gumenyuk, T., Udris-Borodavko, N., Penchuk, O. Entrepreneurship model for creation of designer competences in the process of professional training. Journal of Entrepreneurship Education, 22(6), 2019.

[3] Kapilevich L.V., Bredikhina Yu.P. Pair motor coordination action in sportsmen (on the example of ballroom dancing). Bulletin of Siberian Medicine; 12(2): 204-210, 2013. https://doi.org/10.20538/1682-0363-2013-2-204-210

[4] Trach, Y., Tolmach, M., Chaikovska, O., Gumeniuk, T. Problems of Cultural Heritage Preservation in the Context of the Armed Conflict Growth. IFIP Advances in Information and Communication Technology (4th IFIP TC 5 DCITDRR International Conference on Information Technology in Disaster Risk Reduction, ITDRR 2019, 575 IFIP, pp. 31-44, 2020.

[5] Sabadash J., Petrova I., Oriekhova S., Polishchuk L., Haidukevych K., Otrishko, M., Historical, cultural and tourist monuments as a factor in the development of territories, International Journal of Advanced Research in Engineering and Technology, 11 (6), pp. 485-493, 2020.

[6] Shinichiro, I.Mechanism of human and animal movement, The Proceedings of the Bioengineering Conference Annual
Meeting of BED/JSME 2018. 30:15AM3, 2018. https://doi.org/10.1299/jsmebio.2018.30.15AM3

[7] Delp, S., Loan, J. A computational framework for simulating and analyzing human and animal movement, Computing in Science and Engineering, 2(5), pp. 46 - 55, 2000. https://doi.org/10.1109/5992.877394

[8] Keogh, J. Introduction to a New MDPI Open Access Journal: Biomechanics, 2021. https://doi.org/10.3390/biomechanics 1010013

[9] Rutherford, D.J. Dance with biomechanics, Osteoarthritis and Cartilage, 29: S9, 2021. https://doi.org/10.1016/j.joca. 2021.02.024

[10] Romanenko V., Veretelnikova N. , "Assessment of biomechanical characteristics in impact combats using mobile computer application," Edinoborstva, Vol. 2, No. 12, pp. 48-57, 2019. http://doi.org/10.5281/zenodo.2544678

[11] Kashuba V., "Video-computer analysis of sportsmen's posture," Science in Olympic Sports, No. 3-4, pp. 71-74, 2002.

[12] Kashuba V.A., Litvinenko Yu.V., Danilchenko V.A., "Modelling movement in sports training," Physical education of students, Vol. 4/2010, pp. 40-44, 2010.

[13] Khaled M., "Computersimulation zur biomechanischen Diagnose des Gewichthebens,": Dissertation zur Erlangung des akademischen Grades des Doctors der Sozialwissenschaften an der Universität Konstanz, Fachbereich Geschichte und Soziologie, 2003, 119 p.

[14] Krupenya S., Khmelnitskaya I., "Biomechanical analysis of the gymnasts' sports technique in the vault," LAP LAMBERT Academic Publishing, 2015, 280 p.

[15] Lysykh A.V., "Biomechanical analysis of attacking actions of foil fencers and experimental substantiation of ways; experimental substantiation of ways to improve their technical training," Ph.D. dis. for sch. degree of Cand. ped. sciences: 13.00.04. GTsOLIFK., 1989, 22 p.

[16] Gabovich M., "Principles of Biomechanics in Classical Dance Teaching Methods," Ph.D. dis. for sch. degree of Cand. History of Arts: 17.00.01., 187p., 1986.

[17] Tarkhanov I., "Biomechanical structure of back steps in dance sports," Ph.D. dis. for sch. degree of Cand. ped. sciences: 01.02.08., 2016, $131 \mathrm{p}$. 